\title{
Uso de psicotrópicos por acadêmicos da área da saúde: uma análise comparativa e qualitativa
}

\section{Use of psychotropic drugs by students from the health area: a comparative and qualitative analysis}

\author{
João Borges Esteves Tovani' (1) |johnny.tovani@gmail.com \\ Luísa Jobim Santi' (D) lujobimsanti98@gmail.com \\ Eliana Villar Trindade ${ }^{1,2}$ (D) eliana.trindade@ceub.edu.br
}

\section{RESUMO}

Introdução: O consumo inadequado de psicotrópicos é bastante prevalente entre universitários da área da saúde. Essa situação reflete uma inversão de valores, em que os futuros profissionais orientadores sobre o consumo de drogas fazem seu uso indevido.

Objetivo: Esta pesquisa visa realizar um estudo epidemiológico descritivo do perfil de consumo de drogas por acadêmicos da área da saúde, bem como analisar o significado subjetivo do uso de drogas para os universitários.

Método: Trata-se de um estudo transversal, cuja amostra quantitativa foi de 745 estudantes, de 15 a 70 anos, dos cursos de Psicologia, Medicina, Enfermagem, Nutrição e Fisioterapia. Empregou-se, para a coleta de dados, o questionário adaptado do I levantamento nacional sobre o uso de álcool, tabaco e outras drogas entre universitários das 27 capitais brasileiras. No que diz respeito ao trabalho qualitativo, foi realizado um grupo focal cujos participantes foram dez estudantes, sendo três de Psicologia, três de Fisioterapia, um de Medicina e um de Enfermagem.

Resultado: Os resultados da pesquisa apontam que as substâncias psicotrópicas mais utilizadas pelos participantes foram: álcool, tabaco e maconha, além de tranquilizantes e ansiolíticos. Ademais, em comparação com outros cursos, Psicologia liderou o usou drogas em geral, seguido de Nutrição e Medicina. Além disso, percebeu-se o uso de drogas como meio de fuga em relação ao sofrimento psíquico, bem como forma de maximização do prazer. Para os universitários, o uso de psicotrópicos é tido como amálgama das relações interpessoais, sendo influenciado também pelo desejo de melhora no desempenho acadêmico.

Conclusão: Os dados da pesquisa revelaram um alto consumo de psicotrópicos entre universitários da saúde, condição atrelada a sofrimento psíquico e que revela uma demanda por aporte e auxílio em termos de dependência a substâncias. É importante que novas pesquisas a respeito do tema sejam realizadas, para que efetivas políticas públicas possam ser implementadas.

Palavras-chave: Uso de Psicotrópicos; Estudantes Universitários; Cursos da Área da Saúde.

\section{ABSTRACT}

Introduction: The use of psychotropic substances is highly prevalent among students in the health area. This situation reveals an inversion of values, in which future professionals who will give advice on drug use and abuse make inadequate consumption of drugs.

Objective: This research aims to collect and comparatively analyze the profile of psychotropic substance use by health students, as well as analyze the subjective significance of drug use by health students.

Methods: This is a cross-sectional study, with a quantitative sample of 745 students, aged 15 to 70 years, from the Psychology, Medicine, Nursing, Nutrition and Physiotherapy courses. A questionnaire adapted from the "I National Survey on the Use of Alcohol and Other Drugs by University Students in the 27 Brazilian Capitals" was used for data collection. Regarding the qualitative work, a focal group was carried out, whose participants comprised ten students, of which three were Psychology students, three were Physiotherapy students, one was a medical student and one a Nursing student.

Results: The study results showed that the psychotropic substances most often used by the participants were: Alcohol, Tobacco and Marijuana, in addition to Tranquilizers and Anxiolytics. Furthermore, in comparison with the other courses, Psychology students were the ones who used the most drugs in general, followed by Nutrition and Medicine. Moreover, drug use was perceived as a means of escape from psychological distress, as well as a way to maximize pleasure. For university students, the use of psychotropic drugs is seen as an combination of interpersonal relationships, being also influenced by the desire to improve academic performance.

Conclusion: The study data disclosed a high consumption of psychotropic drugs by university students in the health area, a condition associated to psychological distress and which reveals a demand for support and assistance in terms of substance dependence. It is important that further research on the subject be carried out, so that effective public policies can be implemented.

Keywords: Psychotropic Substance Use; University Students; Health Courses.

${ }^{1}$ Centro Universitário de Brasília, Brasília, Distrito Federal, Brasil.

${ }^{2}$ Universidade de Brasília, Brasília, Distrito Federal, Brasil.

Editora-chefe: Rosiane Viana Zuza Diniz.

Editor associado: Maurício Abreu Pinto Peixoto.

Recebido em 24/01/21; Aceito em 11/07/21.

Avaliado pelo processo de double blind review. 


\section{INTRODUÇÃO}

O consumo inadequado de drogas por universitários é bastante prevalente na sociedade atual ${ }^{1-3}$, principalmente por estudantes de Medicina e outras áreas da saúde ${ }^{4-6}$, como Psicologia, Fisioterapia, Nutrição, entre outras. Embora seja um grave problema de saúde pública, o uso de psicotrópicos ainda é uma questão negligenciada e não tem um foco específico para atuação.

Entende-se o consumo de psicotrópicos como uma prática milenar, visto que, em todas as civilizações e épocas, substâncias psicoativas foram consumidas pelo homem como meio de afetar sua existência ${ }^{7,8}$. Entretanto, foi constatado um assustador aumento na frequência de uso e abuso de drogas na contemporaneidade ${ }^{9}$.

No cenário contemporâneo atual, a exterioridade se tornou o valor vigente: os signos externos, como bens de consumo e status social, tornaram-se demarcadores do papel de cada um ${ }^{10}$. Nesse contexto, os destinos do desejo assumiram um direcionamento exibicionista e autocentrado ${ }^{10,11}$. Marcada pela necessidade de engrandecimento da própria imagem e pela exigência de performance, a busca por satisfação imediata e contínua dos desejos é um valor predominante ${ }^{10,12}$.

Nesse enquadre, o consumo de drogas passou a constituir um dos principais meios de evitar o contato direto com a realidade e com os sofrimentos inerentes à condição humana ${ }^{10,13}$. O uso de psicotrópicos representa uma reposta ao mal-estar, uma tentativa de o sujeito controlar os próprios afetos $^{8,9}$. Ao usar drogas, o sujeito passa a ser regido pelo princípio do prazer, busca realizar uma mutação da realidade, a qual se torna, ao mesmo tempo, rechaçada e recriada, destruída e preservada9. Apesar de buscar romper com os sintomas, o usuário de drogas mantém, em geral, um vínculo com a realidade: ele não a repudia radicalmente, apenas assume uma posição de onipotência na qual tem controle sobre a obtenção de gozo e afastamento do mal-estar ${ }^{9}$.

Apesar de as drogas serem consumidas pela população de forma geral, constata-se um maior uso de psicotrópicos entre os universitários ${ }^{1-3}$. Por serem majoritariamente jovens, os universitários apresentam o seguinte perfil: fase de exploração da identidade, especialmente nos relacionamentos amorosos e no trabalho; transição entre adolescência e vida adulta; instabilidade emocional e do status educacional; afastamento dos valores familiares; inserção em uma época de possibilidades e oportunidade para transformação da própria ${ }^{14}$.

A juventude é marcada por processos subjetivos que visam suprimir as falhas inerentes à estrutura social em atribuir à pessoa um lugar de harmonia com sua condição de ser desejante ${ }^{15}$. Nesse período, o ciclo social é um fator que exerce grande influência sobre o desenvolvimento psíquico dos jovens, os quais, como meio de obter de apoio e cumplicidade dos pares, tendem a manifestar desejo de experimentar estados diferentes de consciência induzidos por psicotrópicos. Isto é, a faixa etária dos universitários constitui uma variável contribuinte para a percepção equivocada do uso de drogas ${ }^{14}$. Além do ciclo social, fatores como transformações biológicas/ hereditárias ${ }^{16}$ e caracteres hormonais ${ }^{17}$, sexuais e neurológicos ${ }^{18}$ também exercem influência no uso de substâncias psicoativas.

Entre a multifatoriedade de variáveis que influenciam o consumo exacerbado de drogas, encontram-se as comorbidades psiquiátricas ${ }^{19}$, como a depressão e ansiedade, muito comuns nos cursos da área da saúde ${ }^{20}$. Além disso, o manuseio de psicotrópicos está atrelado a uma predisposição à dependência química $^{1,12,21}$ e a comportamentos de risco, como múltiplas parcerias e violência física ${ }^{1,22}$. Entende-se que o uso de drogas é realizado por diferentes motivos e gera diferentes sentidos para cada usuário ${ }^{23}$. No caso dos universitários da área da saúde, o fácil acesso a diversas substâncias e a convivência com elas, bem como condições de trabalho e estudo estressantes ${ }^{6}$, são variáveis que corroboram o elevado uso de psicotrópicos entre esse público.

Entende-se que, apesar de o homem ter um papel de protagonista na construção de si mesmo, um indivíduo não existe fora do campo sociocultural ${ }^{24,25}$. No caso da sociedade atual, que repousa em um modelo de produção capitalista, em que há uma compulsão por trabalho e renúncia ao instinto, a satisfação repousa em seu orgulho pelo que já foi alcançado com êxito ${ }^{26}$. Essa constituição é percebida entre os universitários da área da saúde à medida que o desempenho acadêmico individual passa a ocupar papel de protagonismo na vida dos estudantes: nesse contexto, o uso de drogas tem o papel de aprimorar o desempenho acadêmico, bem como atua como meio de maximização do prazer e fuga do sofrimento psíquico ${ }^{27}$. Os psicotrópicos servem como "amortecedores de preocupações", possibilitam que as pessoas se afastem das pressões da realidade, encontrando refúgio em um mundo próprio, com melhores condições de sensibilidade ${ }^{24,27}$. Entretanto, apesar de as drogas, na condição de objeto de gozo, aliviarem momentaneamente o sofrimento psíquico, o recalcado sempre retorna, revelando uma subjetividade "deprimida" pelo excesso de objetos ${ }^{27}$.

Diante dessas informações, percebe-se que o alto consumo de psicotrópicos pela população jovem, em especial universitários da área da saúde, é uma questão de saúde pública que requer estudos aprofundados. Esses estudantes serão os futuros profissionais responsáveis pela propagação de informações relacionadas aos efeitos das drogas e à dependência química ${ }^{4,6}$. Servem como modelo para seus pacientes e têm papel significativo no tratamento deles. Assim, o constante uso de psicotrópicos por esses universitários 
reflete um meio de inversão de valores, em que os próprios profissionais acolhedores e orientadores sobre o uso de substâncias psicoativas fazem seu uso indevido, ou seja, há uma quebra de modelo ${ }^{6}$.

Dentre os problemas graves gerados pelo consumo de drogas, o Relatório brasileiro sobre drogas (RBSD) aponta que o uso de psicotrópicos está frequentemente associado a problemas graves, como acidentes, violência, produção ou agravamento de doenças e queda nas atividades acadêmicas e no trabalho, e pode levar a conflitos familiares e sociais ${ }^{28}$. Assim, a elevação no índice de consumo de drogas contribui para o aumento dos gastos públicos e sociais com tratamentos médicos, com intervenções em casos de violências e outros desdobramentos.

Conforme o RBSD ${ }^{28}$, no Brasil as substâncias psicoativas de maior consumo uso em vida são: álcool (74,6\%), tabaco $(44,0 \%)$, maconha $(8,8 \%)$, solventes $(6,1 \%)$, benzodiazepínicos $(5,6 \%)$, orexígenos $(4,1 \%)$ e estimulantes $(3,2 \%)$. As drogas de maior dependência são as mesmas, apresentando, respectivamente, em valor percentual 12,3\%, 10,1\%, 1,2\%, 0,5\%, $0,2 \%$ e $0,2 \%$ para dependência química. Esses dados refletem as graves repercussões que o uso abusivo de drogas gera na população brasileira, como perda da produtividade e mão de obra de trabalho, vulnerabilidade dos usuários à violência ${ }^{29} \mathrm{e}$ propensão ao adoecimento biológico e mental ${ }^{30}$.

Nota-se que o uso de psicotrópicos por universitários da área da saúde é um tema relevante para o controle e a investigação dos fatores de saúde da população brasileira. Atualmente existem diversos artigos e pesquisas acerca do uso de psicotrópicos por universitários de Medicina ${ }^{2,4,5}$. Entretanto, há uma escassez de pesquisas que investiguem o uso de drogas por estudantes dos demais cursos da área da saúde, assim como se evidencia um hiato de uma década ou mais quanto a estudos e análises comparativas dessa temática. Entre os poucos estudos acerca do uso de drogas por estudantes de diferentes cursos da área da saúde, a maior concentração de pesquisas de análise comparativa tem perdido a incidência ao longo dos anos, com um hiato de uma década ou mais ${ }^{2,6}$.

\section{Objetivos}

Pautando-se pela carência de pesquisas recentes acerca do uso de psicotrópicos por universitários das diversas áreas da saúde, esta pesquisa tem por objetivo analisar a prevalência do consumo de psicotrópicos por discentes dos seguintes cursos da área da saúde: Medicina, Enfermagem, Psicologia, Nutrição e Fisioterapia. Este estudo tem também como propósito compreender o significado subjetivo do uso de drogas para os alunos desses cursos.

\section{MÉTODO}

Realizou-se um estudo transversal analítico com triangulação de métodos quantitativo e qualitativo. A pesquisa foi composta por duas etapas: 1. aplicação de um questionário quantitativo e 2. realização de um grupo focal. Participaram da primeira etapa 745 estudantes voluntários de todos os turnos dos cursos de Medicina, Psicologia, Enfermagem, Nutrição e Fisioterapia do Centro Universitário de Brasília (UniCeub), uma universidade privada de Brasília. Por meio do cálculo amostral em pesquisa ${ }^{31}$, obtiveram-se para cada curso, respectivamente, 169, 222, 166, 114 e 73 participantes. Os estudantes que participaram da pesquisa tinham entre 15 e 70 anos, sendo 572 mulheres (78,04\%) e 161 homens (21,96\%). Quatorze pessoas não informaram o sexo.

Para a coleta de dados, aplicou-se um questionário adaptado de autopreenchimento com 71 questões objetivas. Esse instrumento foi validado e utilizado anteriormente na pesquisa da Secretaria Nacional de Políticas sobre Drogas para o I levantamento nacional sobre o uso de álcool, tabaco e outras drogas entre universitários das 27 capitais brasileiras ${ }^{1}$. Este artigo concentra-se nos resultados pertinentes à questão 26 do questionário, a qual teve por objetivo levantar informações sobre o uso de drogas nos últimos 12 meses e nos últimos 30 dias das seguintes substâncias: álcool, tabaco, maconha, alucinógenos, cocaína, anfetaminas, anticolinérgicos, solventes orgânicos, tranquilizantes, ansiolíticos, opiáceos, sedativos e barbitúricos.

O projeto foi submetido ao Comitê de Ética e aprovado na $15^{\text {a }}$ Reunião Ordinária do Comitê de Ética em Pesquisa (CEP) do UniCeub, em 24 de agosto de 2018, com Parecer no 2.830.452/18. Posteriormente à sua aceitação, foram divulgados convites de participação aos estudantes dos cursos da área da saúde supracitados. Coletaram-se os dados durante o segundo semestre de 2018 e o primeiro de 2019. O questionário foi aplicado em salas de aula pelos examinadores, que deram orientações sobre o preenchimento e reforçaram a confidencialidade e os benefícios do projeto. Todos os participantes voluntários foram instruídos a preencher o Termo de Consentimento Livre e Esclarecido antes de responderem aos questionários. A computação e a análise quantitativa transversal com cruzamento de dados foram realizadas pelo grupo estatístico ESTAT.

Já a etapa qualitativa foi realizada com dez estudantes: três de Psicologia, uma de Medicina, uma de Enfermagem e três de Fisioterapia. Nessa etapa da pesquisa, realizou-se uma análise da subjetividade dos participantes para verificar como avaliavam a experiência do uso de drogas e obter deles as opiniões, os sentimentos e os significados vinculados a essa temática.

Para a realização do grupo focal, elaborou-se um roteiro com cinco tópicos, nos quais constavam questões norteadoras 
sobre a interpretação do que é droga e o significado subjetivo do uso dela. Levantaram-se vivências, motivações, apreensões, bem como fatores de risco e de proteção, construção de identidade, benefícios e prejuízos do uso de psicotrópicos, iatrogenia dentro de cada curso e também preconceitos acerca do tema. Objetivouse, portanto, a significação desse uso para os estudantes, tendo o moderador o papel de encorajar os depoimentos e expressar os tópicos em forma de estímulos e questões abertas.

Este artigo tem como foco a compreensão dos resultados da análise descritiva bivariada dos dados e a análise da significação do uso de drogas pelos universitários. Na parte quantitativa, calcularam-se as porcentagens de uso na vida, no último ano e no último mês para cada droga, além da prevalência desse consumo pelas categorias gênero/sexo, anos de curso e curso da área da saúde. Para a representação desses valores, utilizaram-se tabelas com todos percentuais, e, para os critérios de discussão, compararam-se resultados dos estudantes do UniCeub com os dados da Secretaria Nacional de Políticas sobre Drogas ${ }^{1}$.

Na parte qualitativa, para uma melhor compreensão da subjetividade dos participantes da pesquisa, foi elaborada uma análise do discurso, fundamentada na teoria psicanalítica. $\mathrm{O}$ discurso consiste em uma prática de linguagem e expressão, e sua análise busca ampliar a compreensão acerca de como o homem significa o que está à sua volta e em si mesmo. Assim, a análise do discurso considera que, ao comunicar algo, a pessoa promove uma significação do que é dito. Logo, cabe ao pesquisador desvendar o sentido empregado pelo sujeito em sua fala.

\section{RESULTADO}

\section{Análise descritiva bivariada}

Com base na Tabela 1, percebe-se que as drogas mais utilizadas durante a vida por estudantes da área da saúde do UniCeub foram: álcool (90,16\%), tabaco $(45,19 \%)$, maconha $(39,56 \%)$, inalantes e solventes $(17,05 \%)$ e tranquilizantes (14,57\%). Nos últimos 12 meses antes da aplicação do questionário, as substâncias mais consumidas foram: álcool (78,60\%), tabaco (32,89\%), maconha $(27,52 \%)$, tranquilizantes $(11,71 \%)$ e ecstasy (9,98\%). Em relação aos últimos 30 dias, o maior consumo foi de: álcool (64,63\%), tabaco $(29,59 \%)$, maconha $(23,11 \%)$, tranquilizantes $(11,41 \%)$ e ecstasy $(7,69 \%)$.

Diferenças aparentes do uso de substâncias psicoativas foram observadas conforme o gênero/sexo do universitário. Os homens consumiram mais álcool na vida e nos últimos 30 dias que as mulheres. No entanto, existe pouca diferença para as medidas de uso nos últimos 12 meses. Já o uso de tabaco por universitários do sexo masculino foi mais elevado, tanto para o uso na vida quanto para o uso nos últimos 12 meses e nos últimos 30 dias (Tabela 2).
As drogas mais consumidas na vida por homens foram: álcool $(93,12 \%)$, tabaco $(52,79 \%)$, maconha $(48,75 \%)$, inalantes $(21,73 \%)$, ecstasy $(22,78 \%)$ e alucinógenos $(21,51 \%)$. Entre as mulheres, as drogas mais usadas foram: álcool (89,43\%), tabaco e derivados (42,90\%), maconha (36,87\%), tranquilizantes (16,54\%) e inalantes (14,89\%). Para o uso nos últimos 12 meses, as mais consumidas por homens foram: álcool (79,22\%), tabaco e derivados (44,77\%), maconha (36,36\%), ecstasy $(15,12 \%)$, alucinógenos (13,22\%) e inalantes (9,52\%). Já as mulheres, nos últimos 12 meses, consumiram mais: álcool (78,31\%), tabaco $(29,09 \%)$, maconha (25\%), tranquilizantes $(13,25 \%)$, ecstasy (8,82\%) e alucinógenos (6,54\%) (Tabela 2).

Em relação ao consumo nos últimos 30 dias, as substâncias mais consumidas por estudantes do sexo masculino foram:álcool $(67,10 \%)$, tabaco $(36,36 \%)$, maconha $(30 \%)$, ecstasy $(12,17 \%)$, alucinógenos (8,77\%) e opiáceos (7,01\%). Entre as mulheres, as mais relatadas foram: álcool $(63,65 \%)$, tabaco $(27,19 \%)$, maconha $(21,02 \%)$, tranquilizantes $(12,79 \%)$, ecstasy $(6,60 \%)$, opiáceos $(5,98 \%)$ e inalantes $(4,14 \%)$. Além disso, constatou-se que o uso geral de drogas foi significativamente maior entre o sexo

Tabela 1. Uso de substâncias psicotrópicas - geral.

\begin{tabular}{|c|c|c|c|}
\hline & $\begin{array}{l}\text { Uso na } \\
\text { vida (\%) }\end{array}$ & $\begin{array}{l}\text { Uso nos } \\
\text { últimos } 12 \\
\text { meses (\%) }\end{array}$ & $\begin{array}{c}\text { Uso nos } \\
\text { últimos } 30 \\
\text { dias (\%) }\end{array}$ \\
\hline Álcool & 90,16 & 78,60 & 64,63 \\
\hline Produtos de tabaco & 45,19 & 32,89 & 29,59 \\
\hline Maconha e derivados & 39,56 & 27,52 & 23,11 \\
\hline Inalantes e solventes & 17,05 & 6,37 & 4,44 \\
\hline $\begin{array}{l}\text { Tranquilizantes e } \\
\text { ansiolíticos }\end{array}$ & 14,57 & 11,71 & 11,41 \\
\hline Alucinógenos & 13,15 & 7,83 & 4,08 \\
\hline Ecstasy & 12,51 & 9,98 & 7,69 \\
\hline Opióides & 10,80 & 7,71 & 6,12 \\
\hline Drogas sintéticas & 4,38 & 3,06 & 2,48 \\
\hline Codeína e derivados & 4,38 & 2,33 & 2,21 \\
\hline Cocaína & 3,52 & 1,37 & 0,91 \\
\hline Anfetamínicos & 3,00 & 2,64 & 2,64 \\
\hline $\begin{array}{l}\text { Esteroides } \\
\text { anabolizantes }\end{array}$ & 2,58 & 1,12 & 1,12 \\
\hline Chá de ayahuasca & 2,73 & 1,88 & 1,88 \\
\hline $\begin{array}{l}\text { Sedativos e } \\
\text { barbitúricos }\end{array}$ & 2,72 & 2,14 & 1,90 \\
\hline Cetamina & 1,14 & 1,14 & 1,14 \\
\hline Anticolinérgicos & 0,95 & 0,95 & 0,95 \\
\hline Heroína & 0,56 & 0,56 & 0,56 \\
\hline Crack & 0,37 & 0,37 & 0,37 \\
\hline Merla & 0,36 & 0,36 & 0,36 \\
\hline
\end{tabular}


masculino, exceto nas ocasiões de tranquilizantes e opiáceos em uso na vida e nos últimos 12 meses, em que o sexo feminino sobressaiu (Tabela 2).

A partir da Tabela 3, percebe-se que o consumo de álcool entre os universitários da área da saúde foi maior entre alunos do primeiro (78,9\%), segundo (86,24\%) e terceiro $(78,80 \%)$ anos da faculdade, isto é, no início do curso. Os estudantes fizeram menor uso de álcool na categoria "outros anos" (71,43\%), seguida pelo sexto $(76,92 \%)$ e quinto anos $(68,18 \%)$ de curso. Já o uso de tabaco foi mais elevado entre universitários de outros anos da faculdade (50\%), seguido pelo quinto $(45,45 \%)$ e segundo anos (38,04\%) (Tabela 3).

O uso de maconha foi maior no quinto ano $(45,45 \%)$ da faculdade, seguido pelo segundo ano (35,48\%). Os estudantes do início e do final do curso foram os que fizeram menor uso dessa droga, e $18,18 \%$ dos universitários do sexto ano e $29,85 \%$ dos estudantes do primeiro ano tiveram o mesmo índice. O consumo de tranquilizantes e ansiolíticos foi maior no quinto ano da faculdade (26,67\%), seguido pelo índice de "outros anos" (25\%). Os alunos do terceiro $(8,22 \%)$ e quarto anos $(8,49 \%)$ foram os que fizeram menor uso de ansiolíticos e tranquilizantes. Já o consumo de ecstasy foi maior entre os estudantes do quinto ano (18,52\%) e terceiro anos (12,59\%), sendo menor entre alunos do primeiro $(7,41 \%)$ e quarto anos $(7,41 \%)$ (Tabela 3).

$\mathrm{Na}$ Tabela 4, percebe-se que as drogas mais usadas por universitários da área da saúde ao longo da vida foram: álcool, tabaco, maconha, inalantes, alucinógenos, tranquilizantes e ansiolíticos. Entre os cursos do UniCeub, o que apresentou maior índice de consumo de álcool na vida foi o de Psicologia (94,71\%), seguido pelo de Nutrição (92,62\%) e Medicina $(92,45 \%)$. As áreas que apresentaram menor uso de álcool foram Fisioterapia (82,43\%) e Enfermagem (83,12\%). Percebeuse um alto percentual de consumo uso dessa substância pelos universitários de todos os cursos (Tabela 4).

No que diz respeito ao consumo em vida de tabaco, os alunos do curso de Nutrição foram os que fizeram maior uso, seguidos por estudantes de Psicologia (47,58\%), Fisioterapia (41,89\%), Medicina (39,87\%) e Enfermagem (38,85\%). Em relação ao uso de maconha ao longo da vida, os maiores índices foram dos cursos de Nutrição (46,34\%) e de Psicologia (46,26\%), com valores muito próximos. Os universitários do curso de

Tabela 2. Uso de substâncias psicotrópicas por gênero/sexo.

\begin{tabular}{lcccccc}
\hline & \multicolumn{2}{c}{ Uso na vida (\%) } & Uso nos últimos & $\mathbf{2}$ meses (\%) & \multicolumn{2}{c}{ Uso nos últimos 30 dias (\%) } \\
\cline { 2 - 7 } & $\wp$ & $\sigma^{\pi}$ & $q$ & $\sigma^{\pi}$ & $q$ & $\sigma^{\pi}$ \\
\hline Álcool & 89,43 & 93,12 & 78,31 & 79,22 & 63,65 & 67,10 \\
Produtos de tabaco & 42,90 & 52,79 & 29,08 & 44,77 & 27,19 & 36,36 \\
Maconha e derivados & 36,87 & 48,75 & 25,00 & 36,36 & 21,02 & 30,00 \\
Inalantes e solventes & 14,89 & 21,73 & 5,22 & 9,52 & 4,14 & 5,04 \\
Tranquilizantes e ansiolíticos & 16,54 & 8,22 & 13,25 & 6,95 & 12,79 & 6,95 \\
Alucinógenos & 10,57 & 21,51 & 6,54 & 13,22 & 2,88 & 8,77 \\
Ecstasy & 9,54 & 22,78 & 8,82 & 15,12 & 6,60 & 12,17 \\
Opióides & 11,64 & 6,91 & 7,88 & 7,62 & 5,98 & 7,01 \\
Drogas sintéticas & 3,78 & 6,83 & 3,03 & 3,41 & 1,98 & 4,42 \\
\hline
\end{tabular}

Tabela 3. Uso de substâncias psicotrópicas por ano de curso.

\begin{tabular}{lccccccc}
\hline & \multicolumn{7}{c}{ Uso na vida (\%) } \\
\cline { 2 - 8 } & $\mathbf{1}^{\mathbf{0}}$ ano & $\mathbf{2}^{\circ}$ ano & $\mathbf{3}^{\circ}$ ano & $\mathbf{4}^{\circ}$ ano & $\mathbf{5}^{\circ}$ ano & $\mathbf{6}^{\circ}$ ano & Outros anos \\
\hline Álcool & 78,90 & 86,24 & 78,80 & 75,40 & 68,18 & 76,92 & 71,43 \\
Produtos de tabaco & 29,85 & 38,04 & 32,50 & 31,53 & 45,45 & 18,18 & 50,00 \\
Maconha e derivados & 23,00 & 35,48 & 28,40 & 26,61 & 34,38 & 18,18 & 28,57 \\
Inalantes e solventes & 4,62 & 6,82 & 6,08 & 7,89 & 6,67 & 15,38 & 12,50 \\
Tranquilizantes e ansiolíticos & 15,05 & 9,52 & 8,22 & 8,49 & 26,67 & - & 25,00 \\
Alucinógenos & 4,79 & 11,90 & 8,90 & 7,41 & 10,71 & - & 25,00 \\
Ecstasy & 7,41 & 12,05 & 12,59 & 7,41 & 18,52 & 7,69 & 15,50 \\
Opióides & 8,06 & 3,53 & 8,45 & 4,63 & 23,33 & 8,33 & 14,29 \\
\hline
\end{tabular}


Enfermagem (29,30\%) foram os que fizeram menor uso dessa substância (Tabela 4).

Outras drogas de elevado consumo, os alucinógenos, foram mais utilizados ao longo da vida por estudantes de Fisioterapia (18,31\%) e de Psicologia (15,18\%) do UniCeub. Além desse psicotrópico, o consumo de tranquilizantes e ansiolíticos demonstrou ser comum entre os estudantes dos cursos da área da saúde. Os alunos de Enfermagem (21,52\%) e Psicologia $(17,49 \%)$ foram os que fizeram maior consumo dessas drogas, enquanto os discentes de Fisioterapia apresentaram o menor índice de consumo dessa substância (5,56\%).

Além disso, os psicotrópicos mais usados por estudantes dos cursos da área da saúde do UniCeub no último mês foram: álcool, tabaco, maconha, tranquilizantes e ansiolíticos. Os alunos do curso de Medicina (69,22\%) fizeram maior consumo de álcool nos últimos 30 dias, seguidos pelos estudantes de Psicologia (68,01\%), Nutrição (65,80\%) e Fisioterapia (62,86\%).

Em relação ao uso de tabaco, os estudantes de Fisioterapia $(35,08 \%)$ foram os que mais o consumiram nos últimos 30 dias, seguidos por alunos de Nutrição (34,26\%). Os universitários que fizeram menor uso tabaco foram os de Enfermagem (26,31\%). No que diz respeito ao consumo de maconha nos últimos
30 dias, os alunos de Psicologia (30,52\%) fizeram maior uso, seguidos por estudantes de Fisioterapia (24,08\%). Medicina $(16,40 \%)$ foi o curso que obteve menor percentual de consumo dessa droga. Por fim, o uso de tranquilizantes e ansiolíticos nos últimos 30 dias foi mais prevalente entre estudantes de Enfermagem (14,15\%) e, em seguida, de Psicologia (13,64\%).

Como critério de comparação, os dados de consumo de psicotrópicos pelos universitários dos cursos da área da saúde do UniCeub foram contrapostos aos índices de consumo de drogas por discentes de outras localidades do Brasil' ${ }^{1}$.

\section{UniCeub (Tabela 4) versus universidades das 27 capitais brasileiras}

Quando se comparou o consumo de psicotrópicos por estudantes de cursos da saúde do UniCeub ao longo da vida (Tabela 4) com os dados do I levantamento nacional sobre o uso de álcool, tabaco e outras drogas entre universitários das 27 capitais brasileiras ${ }^{1}$, percebeu-se que álcool, ecstasy, maconha e alucinógenos foram mais consumidos por alunos dos cursos da saúde do UniCeub.

A média do uso em vida de álcool entre os universitários das 27 capitais foi de $86,2 \%$, sendo o índice de consumo dessa

Tabela 4. Uso de substâncias psicotrópicas por curso da saúde.

\begin{tabular}{|c|c|c|c|c|c|c|c|c|c|c|}
\hline & \multicolumn{2}{|c|}{ Nutrição } & \multicolumn{2}{|c|}{ Fisioterapia } & \multicolumn{2}{|c|}{ Enfermagem } & \multicolumn{2}{|c|}{ Psicologia } & \multicolumn{2}{|c|}{ Medicina } \\
\hline & Vida & Mês & Vida & Mês & Vida & Mês & Vida & Mês & Vida & Mês \\
\hline Álcool & 92,62 & 65,80 & 82,43 & 62,86 & 83,12 & 54,22 & 94,71 & 68,01 & 92,45 & 69,22 \\
\hline Produtos de tabaco & 52,72 & 34,26 & 41,89 & 35,08 & 38,85 & 26,31 & 47,58 & 61,60 & 39,87 & 23,02 \\
\hline Maconha e derivados & 46,34 & 22,43 & 38,89 & 24,08 & 29,30 & 18,02 & 46,26 & 30,52 & 35,22 & 16,40 \\
\hline Inalantes e solventes & 20,33 & 3,77 & 17,81 & 1,96 & 10,13 & 5,71 & 18,50 & 4,44 & 18,99 & 4,96 \\
\hline Tranquilizantes e ansiolíticos & 13,93 & 8,50 & 5,56 & 10,00 & 21,52 & 14,15 & 17,49 & 13,64 & 8,77 & 8,77 \\
\hline Alucinógenos & 14,05 & 3,77 & 18,31 & 8,16 & 13,29 & 4,95 & 15,18 & 4,57 & 7,05 & 0,93 \\
\hline Ecstasy & 15,83 & 7,62 & 14,08 & 14,26 & 8,23 & 6,73 & 14,86 & 8,04 & 14,86 & 5,26 \\
\hline Opióides & 8,20 & 4,67 & 13,70 & 9,61 & 20,51 & 11,54 & 8,11 & 5,37 & 5,70 & 1,85 \\
\hline Drogas sintéticas & 5,83 & 4,08 & 6,94 & 6,25 & 3,23 & 1,09 & 5,33 & 1,76 & 1,90 & 0,92 \\
\hline Codeína e derivados & 1,03 & 1,03 & 12,68 & 9,80 & 6,37 & 3,45 & 4,07 & 0,65 & 1,90 & 0,93 \\
\hline Cocaína & 1,64 & 0,96 & 4,11 & 2,00 & 5,70 & 2,83 & 4,87 & - & 0,63 & - \\
\hline Anfetamínicos & 5,79 & 3,88 & 1,39 & 2,04 & 4,49 & 3,12 & 3,12 & 3,12 & 0,92 & 0,92 \\
\hline Esteroides anabolizantes & 3,28 & 1,92 & 4,17 & 2,00 & 1,90 & - & 17,49 & 1,16 & 3,16 & 0,91 \\
\hline Chá de ayahuasca & 2,50 & 1,96 & 2,82 & 2,08 & 3,77 & 3,00 & 2,68 & 1,16 & 1,92 & 1,85 \\
\hline Sedativos e barbitúricos & 2,46 & 1,90 & 2,08 & 2,08 & 5,73 & 5,15 & 2,68 & 0,60 & 0,63 & 0,92 \\
\hline Cetamina & 0,95 & 09,5 & 2,08 & 2,08 & 1,27 & 2,04 & 1,18 & 1,18 & 0,64 & - \\
\hline Anticolinérgicos & 1,92 & 1,92 & 2,04 & 2,04 & 1,90 & 2,06 & 0,45 & - & - & - \\
\hline Heroína & 0,96 & 0,96 & 2,04 & 2,04 & - & - & 0,59 & 0,59 & - & - \\
\hline Crack & 0,95 & 0,95 & 2,08 & 2,08 & - & - & 0,45 & - & - & - \\
\hline Merla & 0,95 & 0,95 & 2,00 & 2,00 & - & - & - & - & - & - \\
\hline
\end{tabular}

Lê-se "vida" como uso na vida e "mês" como uso nos últimos 30 dias. 
droga por universitários de Nutrição, Fisioterapia, Enfermagem, Psicologia e Medicina do UniCeub superior à média nacional. Quanto ao tabaco, o consumo foi de $46,7 \%$ entre universitários das 27 capitais ${ }^{1}$, colocando a média de consumo entre universitários de Nutrição e Psicologia do UniCeub superior à média brasileira. Já o uso de maconha foi mais prevalente entre universitários de todos os cursos da área de saúde do UniCeub. O consumo dessa foi de $26,1 \%$ no estudo em comparação'.

No que diz respeito ao uso de ecstasy e alucinógenos na vida, enquanto a média de uso dos universitários brasileiros é de 7,5\% e 7,6\%, respectivamente', o consumo realizado por estudantes da área da saúde do UniCeub foi significativamente maior, excetuando o índice de uso de alucinógenos por estudantes de Medicina, que ficou dentro da média das capitais brasileiras. Além disso, percebeu-se que o consumo de tranquilizantes e ansiolíticos foi maior nos cursos de Nutrição, Enfermagem e Psicologia do UniCeub ao longo da vida. Nas 27 capitais brasileiras, o índice de consumo dessas substâncias foi de $12,40 \%$ '

Quando se compararam os índices de consumo de drogas no último mês por estudantes da área da saúde do UniCeub com dados das 27 capitais ${ }^{1}$, percebeu-se que o uso de álcool, tabaco, maconha, ansiolíticos e tranquilizantes foi superior entre os alunos do UniCeub. O consumo de álcool por universitários no Brasil foi de 60,5\%. O único curso do UniCeub cujo índice de uso dessa substância foi menor nos últimos 30 dias foi o de Enfermagem.

Em relação ao consumo de tabaco, maconha, tranquilizantes e ansiolíticos por universitários nos últimos 30 dias, constatou-se que os universitários da área da saúde do UniCeub fizeram maior uso dessas substâncias que os universitários das 27 capitais $^{1}$. Ao longo do território brasileiro, o índice de consumo de tabaco foi de 21,6\%; o de maconha, de $9,1 \%$, e o de tranquilizantes e ansiolíticos, de 5,8\%.

\section{Grupo focal}

O uso de drogas como escape ao sofrimento humano: um pedido de socorro silencioso

Para a psicanálise, o sofrimento é compreendido como aquilo que atormenta o ser humano, gera angústia e frustração. Representado pela falta, o sofrimento é inerente aos seres humanos ${ }^{32}$, e, como forma de lidar com ele, as pessoas desenvolvem mecanismos de alívio psíquico, forjando objetos de gozo, os quais buscam recolocar a falta. Entre os mecanismos de alívio do sofrimento, encontram-se a busca pela satisfação irrestrita e a fuga do desprazer ${ }^{24}$.

O abuso e o uso de substâncias psicoativas são compreendidos tanto como forma de maximização do prazer como de fuga do sofrimento psíquico. Ao alterarem a química do corpo, gerarem sensações prazerosas e modificarem as condições de sensibilidade, as drogas permitem que o sujeito se afaste das pressões da realidade e encontre refúgio em um mundo próprio, o que pode ser percebido nas seguintes falas dos participantes:

A realidade é o horrível, as drogas me ajudam a lidar $[$...] me ajudam a enfrentar a realidade (P2).

Maconha melhorou meu desempenho, minha ansiedade e depressão [...] me ajuda [...] faço uso diário [...] pra mim ajuda muito (P3).

O efeito [do tabaco] me desperta [...] por mais que minha pressão abaixe (P1).

Quando se analisam esses relatos, percebe-se que o uso de drogas serve não apenas como meio de afastar os sujeitos do sofrimento, mas também traz um efeito letárgico, provoca uma apatia que faz com que a pessoa sinta a ilusão de que a ansiedade foi eliminada. Entretanto, apesar de os tóxicos assumirem uma função de alento perante o mal-estar, o recalcado sempre retorna, revelando uma subjetividade "deprimida" pelo excesso de objetos de gozo, que suprime também o desejo e a esperança, visto que a falta não é de fato suprida ${ }^{27}$.

No caso dos universitários da área da saúde, percebeuse que o mal-estar vivido por eles se encontra vinculado a uma intensa demanda por um desempenho acadêmico de excelência. Assim, o consumo de psicotrópicos serve como forma de alívio de sofrimento e como meio de melhora do desempenho acadêmico:

Na área da saúde [o uso de substâncias] é maior que nos outros cursos [...] provavelmente porque mexemos com vidas e é um mecanismo para aliviar o estresse (E1).

É muito difícil você se manter na Medicina sem remédios, é muito pesado (F1).

Medicina de longe é o curso da saúde que mais usa psicotrópicos, usam muitos remédios para estudar (F1).

Com base nessas falas, constata-se que os estudantes falaram abertamente de suas experiências pessoais em relação ao uso de drogas. Relataram que, no curso de Medicina, a demanda por excelência acadêmica é ainda maior que nos demais cursos da área da saúde, o que provavelmente provoca um maior uso de psicotrópico. Apontaram ainda que os cursos da área da saúde tendem a usar mais substâncias que os outros, pela maior facilidade de acesso a drogas, pela pressão de lidar com outros seres humanos em sua futura área de trabalho e pelo ritmo desgastante e estressor desses cursos. Notase também que, apesar de os participantes relatarem suas vivências pessoais em relação ao uso de substâncias psicoativas, eles não revelaram um sofrimento explícito, não choraram nem 
demonstraram emoção ao falarem sobre a temática durante a reunião do grupo focal. Compreende-se que houve uma racionalização do sofrimento como um mecanismo defensivo, a partir do qual o indivíduo evita entrar em contato com o sofrimento e o fracasso em lidar com a realidade.

\section{O uso de psicotrópicos por estudantes da área da saúde: da satisfação narcísica à necessidade de inserção social}

Para a psicanálise, apesar de o homem ter um papel de protagonista na construção de si mesmo, a constituição dos sujeitos é perpassada pelo contexto sociocultural ${ }^{24,25}$. No caso, a constituição da sociedade atual é pautada por um modo de produção capitalista, em que os valores vigentes são ligados ao desenvolvimento de competências individuais para o alcance de posições de sucesso ${ }^{26}$. Esse sistema repousa em uma compulsão pelo trabalho e em uma renúncia ao instinto, o que, inevitavelmente, leva à "frustração".

Enquadrada nesse modelo, a satisfação das pessoas tende a ser de natureza narcísica, repousa no orgulho pelo que já foi alcançado com êxito ${ }^{26}$. Essa questão é percebida no relato dos estudantes à medida que eles demonstram grande preocupação em apresentar um bom desempenho acadêmico, isto é, enxergam a aprovação acadêmica como algo de que devem se orgulhar, o que torna essa busca por notas boas um elemento motivador para o uso de drogas.

Apesar da constante fuga do sofrimento por meio do uso de psicotrópicos, é necessário que o indivíduo lide com uma determinada dose de sofrimento e frustração para a constituição da maturidade e de sua subjetividade. Há uma diferença entre sofrimento criativo e sofrimento patogênico: no primeiro, a pessoa elabora estratégias criativas e críticas para lidar com a dor; já o segundo é caracterizado por um sofrimento que gera uma solução desfavorável à saúde, isto é, o sujeito já esgotou todos os recursos defensivos e se encontra em vias de adoecimento ${ }^{33}$.

Você tem que estar bem para transmitir melhora para o paciente (F3).

Fico meio decepcionada comigo mesma, porque [usar psicotrópicos] não é o que indico para os outros [...], mas ao mesmo tempo, sem eles não consigo ficar bem e manter meu desempenho na faculdade (P1).

Nota-se que, em especial nos cursos da área da saúde, em que os futuros profissionais serão os responsáveis pela propagação de informações relacionadas aos efeitos das drogas e à dependência química, o manuseio de psicotrópicos é preocupantemente prevalente ${ }^{4,6}$. Essa situação reflete uma quebra de modelos, em que os próprios profissionais acolhedores e orientadores sobre o uso de substâncias as utilizam de forma indevida ${ }^{26,34}$.
Além da fuga do sofrimento, o consumo de drogas encontra-se muito vinculado à fase de desenvolvimento em que a maior parte dos universitários se encontra. A juventude é uma fase marcada por processos subjetivos que visam suprimir as falhas inerentes à estrutura social de atribuir à pessoa um lugar de harmonia com sua condição de ser desejante ${ }^{15}$. Sendo assim, o ciclo social torna-se muito importante para o desenvolvimento psíquico dos jovens. Nas horas de lazer, é comum que os universitários realizem atividades em grupo com os amigos ${ }^{38}$. Nessas atividades, a maior parte do tempo é despendida em idas a bares ou festas, em que o uso de álcool e outras drogas é frequente. Assim, os estudantes influenciam-se mutualmente em termos de consumir psicotrópicos, o que pode ser constatado pelas seguintes falas:

O uso de drogas está diretamente relacionado ao contexto social (P1).

Droga interfere positivamente na socialização [...] as pessoas se sentem mais à vontade e aturam as pessoas, mesmo de quem não gostam (P2).

A cada dez amigos, oito usam alguma coisa [...] é muito raro alguém nunca ter usado drogas. Se você não usa, você é visto como careta, chato... não te aceitam se você não usar (E1).

A partir do grupo focal, percebe-se a droga como amálgama das relações interpessoais dos universitários, atuando como facilitadora de interação social. Além de os estudantes afirmarem que o uso de psicotrópicos proporciona um sentimento de pertencimento, eles apontaram que o não uso de psicotrópicos pode ter papel de exclusão grupal.

\section{Significação do uso de psicotrópicos para os universitários} da área da saúde

No que diz respeito à compreensão dos universitários do que seriam drogas, apesar de todos os participantes serem de cursos da área da saúde, eles demonstraram ter pouco conhecimento da cientificidade do efeito farmacológico das drogas. As falas demonstraram que eles são leigos, não conhecem em profundidade a epidemiologia e os impactos dos alucinógenos, anabolizantes, tranquilizantes e ansiolíticos, nem a função de cada psicotrópico.

Apesar de não se aprofundarem nessa visão tecnicista, foi destacado o aspecto subjetivo do uso de drogas. Eles ressaltaram a inevitabilidade e o aprisionamento dos psicotrópicos, bem como propuseram uma concepção dual acerca as drogas: podem ser usadas de forma recreativa ou medicamentosa, de forma benéfica ou maléfica. Essas questões podem ser observadas nas seguintes falas:

Droga é tudo aquilo que altera seu sistema, altera sua forma de pensar, falar e agir (E1). 
Psicotrópicos representam necessidade, fuga, morte, depressão, felicidade, algo passageiro, inútil, destrutivo (P2).

Acho que ninguém é "normal" [...] ninguém é livre de nenhuma substância. O uso de substâncias tem dois lados [...]. Vício é todo excesso, é a incapacidade de parar [...] às vezes você não está viciado, mas seu corpo está (P3).

Em relação ao consumo de drogas ilícitas, os universitários relativizaram os efeitos delas quando comparados aos das lícitas. Negaram uma associação direta entre a licitude e a gravidade das substâncias psicoativas. Além disso, constataram a facilidade do acesso a psicotrópicos proibidos pela lei. Eles acrescentaram a ineficácia da guerra às drogas e das atuais políticas públicas do Brasil, pronunciando uma necessidade de as drogas ilegais deixarem de ser estigmatizadas, o que pode ser percebido nas seguintes falas:

\section{[...] [o usuário] consegue drogas em qualquer lugar [...] é muito acessível (P2).}

No Brasil, como a gente proíbe tudo, não sabemos o que estamos tomando [quando se acessam drogas ilegalmente] (P1).

[...] [o uso de drogas] é uma questão de saúde pública e está tratado como questão de violência. A primeira coisa [que devemos fazer quanto ao manejo de psicotrópicos] é descartar o preconceito [...] (P3).

Em oposição à facilidade de acesso às drogas, constatouse que um dos principais mecanismos despertadores da curiosidade dos jovens quanto à experimentação de drogas é o tabu. Os participantes relataram que a temática do uso de drogas é pouco discutida nos âmbitos familiar, escolar e universitário de maneira ampla, neutra e não estigmatizante. Revelaram que as instruções dadas a eles geralmente são de repressão e negação ao uso de psicotrópicos. Entretanto, por não conversarem sobre o tema, não conheceram os efeitos dos psicotrópicos, e esse contexto acabaria por fortalecer um comportamento de rebeldia e curiosidade.

\section{CONCLUSÃO}

Assim como apontado anteriormente, a pesquisa teve por objetivo analisar a prevalência do consumo de psicotrópicos por universitários da área da saúde, bem como compreender o significado subjetivo do uso de drogas por esses estudantes. No que diz respeito ao primeiro objetivo, percebeu-se que os psicotrópicos mais consumidos por universitários de Psicologia, Medicina, Nutrição, Enfermagem e Fisioterapia foram: álcool, tabaco, maconha, tranquilizantes e ansiolíticos. Verificou-se que, em comparação com outros cursos, Psicologia liderou o usou drogas em geral, seguida por Nutrição e Medicina. Além disso, os estudantes de Enfermagem fizeram maior uso isolado de ecstasy. Nutrição liderou o consumo de tabaco em vida e no último ano, ficando em segundo lugar no último mês, atrás de fisioterapia.

Por meio do grupo focal, percebeu-se, como motor do elevado índice de uso de drogas, que os psicotrópicos são tidos como meio de fuga do sofrimento e maximização do prazer, bem como amálgama das relações sociais e meio de buscar um desempenho acadêmico de excelência entre universitários da saúde. No que diz respeito a essa última questão, os universitários ponderaram que o uso de psicotrópicos seria ainda maior no curso de Medicina, visto que os estudantes desse curso seriam mais pressionados a apresentar desempenho de excelência. Essa hipótese não foi corroborada, visto que Medicina se apresentou como terceiro curso com índice mais elevado de uso de drogas. Entretanto, os estudantes de Medicina foram os que mais consumiram álcool no último mês, o que pode estar relacionado com o ambiente estressor inerente ao meio acadêmico desse curso.

De modo geral, os dados da pesquisa revelaram um alto índice de consumo de drogas entre universitários da saúde, condição que revela o sofrimento psíquico dos usuários e reflete uma subversão de papéis, em que os futuros profissionais promotores da saúde fazem uso exacerbado de psicotrópicos. Identificou-se também uma demanda silenciosa dos universitários por aporte e auxílio em termos de dependência das drogas, além de exigências específicas da formação centrada no cuidado humano, o que justifica a necessidade específica de atuação sobre essa população. Ressalta-se uma marcante necessidade de novas pesquisas epidemiológicas e analíticas a respeito do tema, a fim de suprir a escassez de estudos recentes, mas principalmente para que seja possível o levantamento de políticas públicas preventivas quanto ao uso comprometedor de substâncias psicotrópicas por universitários da área da saúde.

Com base nos dados apontados, pode-se afirmar que o objetivo principal da pesquisa foi alcançado. $O$ estudo contribui para a área de debates acerca da temática, identifica a população de risco para o uso de psicotrópicos na área de saúde, bem como analisa a influência do uso recreativo ou vicioso de drogas na qualidade de vida e produtividade dos estudantes. Entretanto, há limitações que merecem ser destacadas, visto que apontam para questões que podem ser mais bem desenvolvidas em pesquisas futuras. Entre essas limitações, encontra-se a dificuldade de generalização dos resultados encontrados. A pesquisa foi conduzida em uma única universidade. Assim, apesar de a amostra de participantes ter sido significativa dentro da instituição em que a pesquisa foi realizada, os índices de consumo de psicotrópicos podem ser alterados conforme o contexto sociocultural e a universidade dos estudantes da área da saúde. 
Além disso, percebeu-se que, em comparação à média nacional', o uso geral de drogas, principalmente álcool, tabaco, maconha, tranquilizantes e ansiolíticos, foi maior entre os universitários da área da saúde da universidade em que a pesquisa foi realizada. É possível que essa diferença significativa se deva à disparidade temporal em que os estudos foram realizados. Assim como mencionado anteriormente, há um hiato temporal entre as pesquisas comparativas e o presente estudo.

\section{CONTRIBUIÇÃO DOS AUTORES}

João Borges Esteves Tovani e Luísa Jobim Santi realizaram a revisão bibliográfica acerca do uso de psicotrópicos por universitários da área da saúde, bem como efetuaram a aplicação de questionários e análise dos dados obtidos por meio da pesquisa. Além disso, em parceria com Eliana Villar Trindade, conduziram um grupo focal e analisaram os dados obtidos por meio desse encontro. Eliana Villar Trindade orientou os demais pesquisadores durante o processo de coleta e análise de dados, bem como na elaboração do artigo.

\section{CONFLITO DE INTERESSES}

Declaramos não haver conflito de interesses.

\section{FINANCIAMENTO}

Declaramos não haver financiamento.

\section{REFERÊNCIAS}

1. Andrade AG, Duarte PCAV, Oliveira LG. I levantamento nacional sobre o uso de álcool, tabaco e outras drogas entre universitários das 27 capitais brasileiras. Brasília: Secretaria Nacional de Políticas sobre Drogas; 2010.

2. Chiapetti N, Serbena CA. Uso de álcool, tabaco e drogas por estudantes da área da saúde de uma universidade de Curitiba. Psicol Reflex Crit. 2007;20:303-13.

3. Coutinho MPL, Araújo LF, Gontiès B. Uso da maconha e suas representações sociais: estudo comparativo entre universitários. Psicol Estud. 2004;9(3):469-77.

4. Kerr-Corrêa F, Andrade AG, Bassit AZ, Boccuto NMVF. Uso de álcool e drogas por estudantes de Medicina da Unesp. Rev Bras Psiquiatr. 1999;21(2):95-100.

5. Machado CS, Moura TM, Almeida RJ. Estudantes de Medicina e as drogas: evidências de um grave problema. Rev Bras Educ Med. 2015;39(1):159-67.

6. Lucas ACS, Parente RCP, Picanço NS, Conceição DA, Costa KRC, Magalhães IRS, et al. Uso de psicotrópicos entre universitários da área de saúde da Universidade Federal do Amazonas, Brasil. Cad Saude Publica. 2006;22(3):663-71.

7. Gellis A. Diagnósticos e psicotrópicos - uma resposta pela psicanálise. Psicol USP. 2000;11(1):107-18.

8. Ribeiro CT. Que lugar para as drogas no sujeito? Que lugar para o sujeito nas drogas? Uma leitura psicanalítica do fenômeno do uso de drogas na contemporaneidade. Ágora (Rio J.). 2009;12(2):333-46.

9. Serreti MAT. Toxicomania: um estudo psicanalítico. Mosaico (Belo Horizonte). 2012;5(2):46-60.
10. Pelegrini MRF. O abuso de medicamentos psicotrópicos na contemporaneidade. Psicol Ciênc Prof. 2003;23(1):38-41.

11. Machado PA, Macedo MMK. Impasses no adolescer: narrativas contemporâneas sobre desamparo e drogadição. Athena Digital: Revista de Pensamiento e Investigación Social. 2019;19(1):118-37.

12. Dockhorn CNBF. O sujeito psíquico e a condição de servidão ao objetodroga: do rigor da psicanálise à pesquisa na escuta [tese]. Porto Alegre: Pontifícia Universidade Católica do Rio Grande do Sul; 2014.

13. Canabarro RCS. Toxicomanias e psicanálise: algumas considerações [dissertação]. Porto Alegre: Universidade Federal do Rio Grande do Sul; 2011.

14. Alves TCTF. Depressão e ansiedade entre estudantes da área de saúde Revista de Medicina. 2014;93(3):101-5.

15. Rosa MD. Adolescência: da cena familiar à cena social. Psicol USP. 2002;13(2):222-41.

16. Huizink AC, Levalahti E, Korhonen T, Dick DM, Pulkkinen L, Rose RJ, et al. Tobacco, cannabis, and other illicit drug use among Finnish adolescent twins: causal relationship or correlated liabilities? J Stud Alcohol Drugs. 2010;71:5-14.

17. Lopez $\mathrm{HH}$. Cannabinoid-hormone interactions in the regulation of motivational processes. Horm Behav. 2010;58(1):100-10.

18. Urban NB, Kegeles LS, Slifstein M, Xu X, Martinez D, Sakr E, et al. Sex differences in striatal dopamine release in young adults after oral alcohol challenge: a positron emission tomography imaging study with $[(1)(1) \mathrm{C}]$ raclopride. Biol Psychiatry. 2010;68(8):689-96.

19. Nicastri S. Drogas: classificação e efeitos no organismo. In: Secretaria Nacional Antidrogas. Prevenção ao uso indevido de drogas: curso de capacitação para conselheiros municipais. Brasília: Secretaria Nacional Antidrogas; 2008.

20. Mesquita EA, Nunes AJ, Cohen C. Avaliação das atitudes dos estudantes de Medicina frente ao abuso de drogas por colegas do meio acadêmico. Rev Pisquiatr Clín. 2008;35(1):8-12.

21. Pillon SC, O'Brien B, Piedra KAC. A relação entre o uso de drogas e comportamentos de risco entre universitários brasileiros. Rev Lat Am Enfermagem. 2005;13(2):1169-76.

22. Arnett JJ. The developmental context of substance use in emerging adulthood. J Drug Issues. 2005;35:235-54.

23. Fidalgo TM, Silveira DX. Uso indevido de drogas entre médicos: problema ainda negligenciado. J Bras Psiquiatr. 2008;57(4):267-9.

24. Plastino CA. Dependência, subjetividade e narcisismo na sociedade contemporânea. Transgressões. Rio de Janeiro: Contracapa Livraria. 2002, 103-111.

25. Lacan J. O estádio do espelho como fundador da função do eu. In: Lacan J. Escritos. Rio de Janeiro: Jorge Zahar; 1998.

26. Freud S. O futuro de uma ilusão. Edição standart brasileira das obras psicológicas completas de Sigmund Freud. Rio de Janeiro: Imago, 1931. v. XXI.

27. Leão Y. Resistência e psicanálise. Revista Subjetividades. 1975;8(3):755-77.

28. Claro HG, Oliveira MAF, Titus J, Fernandes IFA, Pinto PH, Tarifa RR. Uso de drogas, saúde mental e problemas relacionados ao crime e à violência: estudo transversal. Rev Lat Am Enfermagem. 2015;23(6):1173-80.

29. Eckschmidt F, Andrade AG, Oliveira LG. Comparação do uso de drogas entre universitários brasileiros, norte-americanos e jovens da população geral brasileira. J Bras Psiquiatr. 2013;62(3):199-207.

30. Wagner GA, Andrade AG. Uso de álcool, tabaco e outras drogas entre estudantes universitários brasileiros. Rev Psiquiatr Clín. 2008;35(supl 1):48-54.

31. Miot HA. Tamanho da amostra em estudos clínicos e experimentais. J Vasc Bras. 2011;10:275-8.

32. Turato E. Métodos qualitativos e quantitativos na área da saúde: definições, diferenças e seus objetivos de pesquisa. Campinas: Laboratório de Pesquisa Clínico-Qualitativa da Faculdade de Ciências Médicas, Universidade Estadual de Campinas; 2005.

33. Dejours C. Uma nova visão do sofrimento humano nas organizações. In: Chanlat J. O indivíduo na organização. São Paulo: Atlas; 1996.

34. Tockus D, Gonçalves OS. Detecção do uso de drogas de abuso por estudantes de medicina de uma universidade privada. J Bras Psiquiatr. 2008;57(3):184-7. 